\title{
Adelaide Chao'
}

\author{
Sociabilidade e consumo da Feira das Yabás: uma \\ observação entre práticas culturais, memória e tradição
}

\author{
Sociability and consumption of Feira das Yabás: an \\ observation between cultural practices, \\ memory and tradition
}

\begin{abstract}
RESUMO
Almoço de domingo, momentos de celebração, comida caseira e música boa no "quintal da casa de vó". Partindo da observação e análise da sociologia da refeição para novas práticas e modos de consumo, este trabalho apresentará a Feira das Yabás - um evento de gastronomia e música que acontece aos domingos na Praça Paulo da Portela em Oswaldo Cruz (bairro do subúrbio carioca) desde 2008 e que reproduz a culinária de quintal através de matriarcas tradicionais da região da Grande Madureira. O propósito deste trabalho é discutir, dentro do cenário urbano da festa popular, as formas de sociabilidade e consumo de alimentos e música de seus atores sociais, propiciados pelo lugar e exaltação no espaço público da rua. Compartilhar o balde cheio de gelo e bebidas, dividir um prato de petiscos, utilizar acessórios da moda carnavalesca das escolas de samba são algumas observações da forma lúdica de sociação e da comensalidade. O trabalho exibirá o resultado parcial de uma pesquisa de campo que apresenta as relações entre imaginário e comunicação do evento: o que define a chamada "comida de subúrbio", as preferências gastronômicas, atrações musicais e costumes da região. Seguindo o eixo temático de valorização das tradições e da cultura popular, esse texto enfatiza as representações das práticas socioculturais contemporâneas da Feira das Yabás, atreladas à história cultural da cidade.
\end{abstract}

Palavras-chave: cidade; consumo; cultura comunitária; comida de subúrbio; sociabilidade; memória.

\begin{abstract}
Sunday lunch, celebration moments, home-cooked food and good music in the "grandma's backyard". Starting from the observation and analysis of the sociology of meal for new practices and modes of consumption, this paper will present the Feira das Yabás - a gastronomy and music event that takes place on Sundays at Paulo da Portela Square in Oswaldo Cruz (suburb of Rio de Janeiro) since 2008 and which reproduces backyard cuisine through traditional matriarchs from the Grande Madureira region. The purpose of this paper is to discuss, within the urban scene of the popular party, the forms of sociability and food and music consumption of its social actors, provided by the place and exaltation in the public space of the street. Sharing the bucket full of ice and drinks, sharing a plate of snacks, using carnival-style accessories from the samba schools are just some of the playful form of socializing and commensality. The work will show the partial result of a field research that presents the relations between imaginary and communication of the event: what defines the so-called "suburban food", the gastronomic preferences, musical attractions and customs of the region. Following the thematic axis of appreciation of traditions and popular culture, this text emphasizes the representations of contemporary socio-cultural practices of Feira das Yabás, linked to the cultural history of the city.
\end{abstract}

Keywords: city; consumption; community culture; suburb food; sociability; memory.

1 Publicitária, doutoranda e Mestre em Comunicação pela UERJ, pesquisadora dos Laboratórios CAC-CNPq (Comunicação, Arte e Cidade), LACON-CNPq (Comunicação e Consumo) e LCC-CNPq (Cidades Criativas) da ESPM Rio. Email: adelaide.chao@gmail.com 


\section{INTRODUÇÃO AO CAMPO DE PESQUISA}

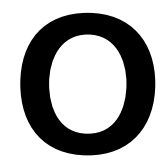

bservar o campo de pesquisa, experienciar o cotidiano da cidade. Este artigo reflete algumas observações acadêmicas que durante sete anos fizeram parte de minha tese de doutorado sobre as ressignificações do subúrbio carioca através de práticas realizadas por mulheres representantes da cultura da cidade - a Comida de Subúrbio. Em parceria com o Prof. Dr. João Maia (1961-2018), do programa de pós-graduação em Comunicação da Universidade do Estado do Rio de Janeiro, realizamos vários estudos sobre as representações do subúrbio carioca e fomos desvelando a história cultural de seus territórios, observando, ouvindo as histórias miúdas, os "causos" do homem comum que vive o cotidiano citadino. Os procedimentos metodológicos que nos norteiam partem de técnicas de observação participante, descrição densa e detalhada do campo de pesquisa e de seus atores sociais (GEERTZ, 2008, 1997; WINKIN, 1998).

Ter o privilégio da companhia e orientação do pesquisador e comunicólogo João Maia foi fundamental para entender a cidade como campo científico e esmiuçar as formas de sociabilidade presentes na cultura das cidades, em especial o Rio de Janeiro, tendo os movimentos comunicacionais como ponto de partida para sua discussão e análise (MAIA, 2012).

Durante seis anos juntos, pude compreender as relações entre a história cultural, a memória e o imaginário que sustentam a Feira das Yabás ${ }^{2}$ enquanto evento propulsor da cultura, do consumo e de uma socialidade muito particular do subúrbio carioca. Observamos o dia-a-dia-de mulheres, matriarcas, suas histórias de vida, sofrimentos e reinvenções, atrelados ao ritmo do cotidiano e das memórias da cidade. Ressaltamos a importância das narrativas e das vozes propulsoras de comunicação e cidadania desses atores sociais. Sobre a importância de tais falas e do tempo lento (no caso da pesquisa com o subúrbio e as yabás), Maia salienta que

\footnotetext{
O ritmo da vida se transforma quando o tom dos fatos narrados por personagens que não tinham espaço de fala, aparece compondo o quadro do todo social. Surge uma forma original do homem olhar a sua própria cidade quando ele mesmo narra a sua vida compartilhada nas ruas [...] Esta fala miúda e fragmentada requisita a nossa atenção aos pequenos elementos constitutivos da cultura que um dia foi chamada de popular. (MAIA, 2005b, p.2)
}

É a toada do cidadão comum que ganha espaço e importância na sua comunidade e, consequentemente, na cultura da cidade. A crescente pluralidade de "tribos" urbanas expõe a variedade de perspectivas sobre o mundo e algumas vezes assistimos as significações específicas de cada grupo, se chocando e se entrecruzando. O problema que se coloca, se pensarmos em termos de metodologia de pesquisa no campo da comunicação e cultura, está concentrado na legitimação dos "subuniversos" cada dia mais fragmentados fazendo surgir a diversidade de falas oriundas de lugares pouco observados. $O$ ator social e os pesquisadores devem reconhecer 0

2 De origem iorubana (dialeto africano), o termo Yabá (labá, Aiabá ou Oiá) significa "rainha", "mãe", "senhora idosa", "aquela que acolhe e alimenta seus filhos". 
"subuniverso" como algo constantemente importante e necessário. A dificuldade de legitimação de certos grupos se torna evidente exatamente pela diversidade. Os autores introduzem a noção de "reificação" da realidade social para pensar a relação do homem com o mundo em fragmentação (MAIA, 2005a, p.81).

Trabalhamos o conceito de tribos urbanas, apoiados nas pesquisas e apontamentos de Michel Maffesoli sobre a sociologia da vida cotidiana, fragmentada e polissêmica - a pluralidade dos aspectos da vida social. Há uma mudança de paradigma, na qual o social (em que o indivíduo tem uma função na sociedade) dá lugar à socialidade - a pessoa representa papéis no theatrum mundi, tanto profissionalmente quanto no seio das tribos de que participa. Nas tribos, a aparência (estética) é importante como vetor de agregação, como cimento social, enquanto que a teatralidade instaura e reafirma a comunidade. Cada indivíduo é ao mesmo tempo, ator e espectador. Para Maffesoli (1998, p.221), a socialidade é "o societal em ato" - é a experiência e o relativismo que apontam para um fazer em comum e para um sentir em comum que está no cotidiano dos gestos e dos fazeres das ruas, das feiras e que além disso, estruturam a vida sem qualidade, tantas vezes tida como insignificante.

Maffesoli (1998) reflete sobre a liberdade do ir e vir, entrar e sair, que os integrantes de uma tribo têm a qualquer momento, por qualquer ocasião. A cidade é o melhor campo comunicacional - as luzes, a escuridão das ruas, os lugares de má fama, as obras monumentais, o trabalho e o prazer.

As observações na Feira das Yabás foram livres e não ocorreu a "busca pelo entrevistado ideal". A partir do momento de interação, as entrevistas presenciais aconteceram - na maioria das vezes - sem que houvesse a necessidade de identificar a finalidade do questionamento, na intenção de obter respostas naturais. A pesquisa desenvolvida não foi um trabalho de perguntas e respostas, mas uma análise a partir de observações com e sem perguntas específicas. É imprescindível manter o estado das coisas e das pessoas (WINKIN, 1998, p.140).

A partir de tais observações metodológicas, consideramos as yabás como "agentes culturais" de seus territórios. São mulheres que vivem comunitariamente, mostrando aí a sua resistência ao modelo de organização social moderno, abusando na criação de seus próprios projetos de vida e da elaboração de produtos culturais que circulam pela cidade. De maneira abusada, sem licença e sem permissão, divulgam seu estilo de vida comunitário para o mundo gerando a diversidade de valores e embaralhando os elementos que estariam separados hierarquicamente. Cidadãs que utilizam os valores da cultura comunitária para negociar sua inserção na cidade (MAIA, 2005b).

O linguista americano George Yudice defende a cultura como recurso, inclusive como recurso de cidadania. Os direitos culturais abrangem a liberdade do engajamento e identificação nas atividades e grupos culturais de suas escolhas, exploram a variedade de culturas, compreendem o patrimônio cultural, desvelam os direitos humanos e atentam, com especial relevância, para "não deixar representar-se sem consentimento ou ter seu espaço cultural utilizado para publicidade, e ganhar respaldo público para salvaguardar esses direitos" (YUDICE, 2013, p. 43). 
Para o cenário da cultura local, brasileira, regionalizada no subúrbio carioca, ancoro-me na reflexão de que a fruição e o consumo são indispensáveis para a completude do circuito cultural que se expressam na singularidade de não serem realizadas por profissionais, e sim por todos os cidadãos (singulares e únicos na dinâmica social da cultura). A não-profissionalização não limita essa fruição e consumo, "garantindo a amplitude e a universalidade do ato de recepção da cultura e a importância central dos públicos culturais" (RUBIM, 2017, p.18-19). Para ilustrar as análises em cenário mais amplo, Rubim, pesquisador de políticas culturais, classifica ações e estratégias de articulação para viabilizar e manter a dinâmica cultural: a) Criação, invenção e inovação; b) Difusão, divulgação e transmissão; c) Preservação e proteção; d) Circulação, cooperação, intercâmbio e troca; e) Análise, crítica, estudo, investigação, pesquisa e reflexão; f) Fruição, consumo e públicos; g) Organização da cultura (IDEM, 2017, p.19).

Em sociedades menos complexas e movimentos locais, a exemplo da Feira das Yabás, tais ações podem ser desempenhadas simultaneamente por várias pessoas com diferentes funções culturais. A yabá que faz a comida, vende, interage com seu público, conta suas histórias miúdas do cotidiano muitas vezes fazendo referência à sua parentalidade, revelando tal importância na construção da identidade cultural do subúrbio carioca, da gastronomia dos quintais e da relação com a música popular brasileira.

"O agente cultural possui uma relação intrínseca com sua comunidade cultural" (RUBIM, 2017, p. 25). Associar as yabás como agentes culturais é constatar que elas encaram o relacionamento com o território que dá sentido à sua experiência de vida como dimensão para desenvolver a cultura, a cidadania e os direitos por uma perspectiva cidadã, sem desconsiderar as contradições e tensões que perpassam o cotidiano do lugar. Isso não as torna profissionais da cultura (agenciadores), mas legitima-as como "militantes da cultura", ativistas que mobilizam seus territórios em uma perspectiva cidadã.

\section{OS QUINTAIS DAS YABÁS DA GRANDE MADUREIRA}

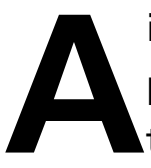

inda não inventaram uma fórmula ou modo de sentir o cheiro das coisas, principalmente da comida - de uma boa e farta comida - por meio dos textos. Em tempo, descrever sobre a Feira das Yabás é convidar o leitor a conhecer as memórias e as histórias do subúrbio carioca, a partir das sensações que a Feira proporciona - o cheiro das comidas, o som dos sambas de raiz, o contato do corpo que dança em comunhão com a praça e com o público, o colorido das barracas e a beleza imagética dos pratos e das pessoas.

Antes de descrever da Feira, suas yabás, quitutes e outras experiências, é necessário situar o território da chamada Região Administrativa da Grande Madureira, formada pelos bairros de Madureira, Oswaldo Cruz, Bento Ribeiro, Campinho, Cascadura, Honório Gurgel, Marechal Hermes, Turiaçu, Rocha Miranda e Vaz Lobo. No contexto de formação da cidade, esses bairros correspondem à Zona Norte, região pouco afastada do centro em relação às periferias. A geógrafa Maria Therezinha 
de Segadas Soares criou o conceito carioca de subúrbio referindo-se a esses bairros como populares e que foram surgindo ao longo da linha férrea, tendo como eixo principal o centro da cidade (BERNARDES e SOARES, 1987; SOARES, 2011; 1960). Embora esse termo não seja adotado pela Prefeitura do Rio de Janeiro, a partir dos anos 2000, a categoria subúrbio carioca é relevante para compreender algumas relações de poder e identidade na cidade (RIBEIRO et al., 2019). O termo "subúrbio" permanece no imaginário coletivo da cidade, não mais em documentos oficiais.

A relação entre quintal e subúrbio iniciou em 1647, quando a atual região da Grande Madureira era conhecida como a Freguesia de Nossa Senhora da Apresentação de Irajá e que incluía os bairros de Vicente de Carvalho, Colégio, Coelho Neto, Pavuna, Penha, Cordovil e Vigário Geral. Fundada no século XVII, a Freguesia de Irajá estava situada no chamado "sertão carioca", onde as fazendas e sesmarias (terrenos abandonados cedidos a agricultores locais) eram responsáveis pela produção vasta de cana-de-açúcar, feijão, mandioca, milho, além da criação de animal para subsistência local. Os portos dos rios Meriti e Pavuna concentravam o escoamento de aguardente e açúcar, além de ser local de comércio de comidas aos trabalhadores do local através de quituteiras da região (CUNHA, 2019). Madureira e Oswaldo Cruz estão localizados na antiga Fazenda do Campinho, passando à propriedade do boiadeiro Lourenço Madureira e nomeados bairros após sua morte no séc. XVIII. Com a chegada do trem e da expansão da malha ferroviária, a partir do final do século XIX, Madureira foi desenvolvendo sua vocação histórica como ponto de encontro e parada de viajantes, convergindo estradas rurais à linhas de trens, tornando-se o principal centro de abastecimento de alimentos da cidade (OLIVEIRA, 2013).

Com a eletrificação dos trens e a expansão geográfica do Rio no século $\mathrm{XX}$, Madureira vai se consolidar como "capital do subúrbio", trazendo a modernidade da cidade urbana, mantendo o bucolismo do habitat rural e favorecendo o desenvolvimento dos bairros em seu entorno. A reforma urbanística do então prefeito Pereira Passos que pretendia "afrancesar" e "higienizar" o Rio de Janeiro, teve o seu auge entre 1905 e 1920, fazendo surgir os bairros dos subúrbios que foram acolhendo a população expulsa de suas moradias dos bairros centrais da cidade. Madureira e Oswaldo Cruz se afirmam como bairros consagrados como polo comercial e também pela consolidação das culturas populares. A região que abriga imigrantes, trabalhadores assalariados e comerciantes, além de ser um reduto da comunidade negra, torna-se o "berço" das grandes escolas de samba da cidade como a Portela, o Império Serrano e do grupo de Jongo da Serrinha. Esta diversidade, marcada pelas culturas africana, nordestina e portuguesa na Região da Grande Madureira foi fundamental para a criação do clima de camaradagem e afirmação de uma identidade suburbana contra o descaso e o abandono do poder público. O carnaval popular reforça essa identidade, mas em período curto do ano (CUNHA, 2019). Para os demais meses, os quintais se transformaram no principal ponto de entretenimento da população do subúrbio, consolidando a influência das culturas de matriz africana, na música, nas artes e, é claro, na culinária. 
Os quintais tornaram-se espaços de celebração. Rodas de samba, ensaios de músicas e sambas de enredo das escolas e blocos carnavalescos, festas religiosas, rodas de jongo aconteciam desde o início do século $\mathrm{XX}$, sempre organizados com comida farta e festa. Mulheres tradicionais como Ester Maria de Jesus, Vicentina, Clementina de Jesus, Doca da Portela, Dona Neném, Surica, Selma Candeia, entre tantas outras, mantiveram seus costumes festivos em seus quintais, representando a afirmação e resistência da cultura de matriz africana, resultando no fortalecimento do espaço do subúrbio e da identidade suburbana (CHAO, 2015).

Pensar os quintais suburbanos, a partir da perspectiva afro-brasileira, é analisar as relações e práticas de passagens entre a casa e a rua. A casa como lugar de ritual privado e a rua como lugar de negociação (RIBEIRO et al., 2019, p. 17). A ideia de quintal enquanto lugar mítico de surgimento do samba no Rio de Janeiro problematiza as tradicionais narrativas de espaço público e privado. Há um entendimento sobre o quintal "enquanto lugar ideal no passado de surgimento das instituições de empoderamento da população negra do Rio de Janeiro". Para os autores, a região compreendida como Grande Madureira, transformou as marcas de origem africana, desde a formação dos bairros suburbanos, em ativos culturais e identitários, necessários ao reconhecimento dessa parcela da população como agente de real definição dessas práticas, tanto para o território (subúrbio carioca) como para seus atores sociais (o suburbano) (IDEM, 2019, p. 8-9).

\section{COMIDA E SAMBA NO PÉ NA FEIRA DAS YABÁS}

riada em 2008, a Feira das Yabás é um evento de gastronomia e música que
recria as práticas e a efervescência dos almoços de domingo em família e
momentos festivos, realizado nos quintais das matriarcas e personalidades importantes da cultura do subúrbio carioca. Nascido em Madureira e criado em Oswaldo Cruz, Marcos Sampaio de Alcântara (1961-), o Marquinhos de Oswaldo Cruz, teve a oportunidade de conhecer pessoas que foram marcantes na sua formação de sambista, compositor e idealizador de projetos culturais. Sua convivência com Antonio Candeia Filho, Sombrinha, Arlindo Cruz, Monarco, Jair do Cavaquinho, Paulinho da Viola, Casquinha, Tia Doca, Tia Neném e Manacéia gerou um aprendizado na música e nas artes, capaz de transformar sua vida profissional. Essa aproximação despertou em Marquinhos a necessidade de divulgar a cultura e o samba do subúrbio para preservar algumas ações culturais que aconteceram nos antepassados de Madureira. Fernandes (2001, p.67) nos detalha com precisão que lá pelos idos de 1926, quando a Portela ainda era o bloco "As Baianinhas de Oswaldo Cruz", seus fundadores - Paulo da Portela, Antonio Rufino e Antonio Caetano - se reuniam embaixo de uma mangueira na Estrada do Portela, 412, onde também funcionava o Bar do Nozinho. Como o espaço era pequeno para tantos sambistas, as reuniões passaram a ser diárias em uma "sede itinerante". Paulo e seus amigos reuniam-se todos os dias no trem que partia às 18:04h na Central do Brasil. No percurso até Oswaldo Cruz, eles realizavam ensaios dos sambas, faziam novas composições, deliberavam novas ações para a recém-nascida Portela. Autores como Fernandes (2001) 
e Silva e Santos (1980) relatam que provavelmente essa "sede itinerante em trilhos" manteve-se por algum tempo, já que aqueles sambistas encontravam uma forma divertida e animada para estabelecer parcerias musicais e artísticas, mesmo após a obtenção da sede fixa em Madureira. Com estes relatos da história cultural do trem, Marquinhos de Oswaldo Cruz idealizou projetos com o intuito de enfatizar a memória e a cultura do subúrbio carioca. No dia 02 de dezembro - Dia Nacional do Samba, Marquinhos recriou o Trem do Samba, um evento que reúne sambistas renomados, ao longo dos 32 vagões dos trens que partem da Central do Brasil até Oswaldo Cruz, iniciado por Paulo da Portela em 1926 (CHAO, 2015).

A fim de enaltecer a gastronomia típica dos quintais de Madureira, Marquinhos começou a pensar em um projeto que evidenciasse a história cultural das festas do subúrbio. As comidas fartas que eram servidas nas rodas de jongo, nos ensaios das escolas de samba, nos almoços de domingo na casa dos baluartes da comunidade com muito samba de roda e partido alto, desde os tempos de Paulo da Portela a Antonio Candeia Filho.

Marquinhos conta que em 2008 reuniu as primeiras yabás ainda na quadra da Portelinha (atual Sede da Velha Guarda da Portela) para uma parceria artística. Ele entrava com o samba e elas com a comida. Começou com a feijoada de Neide Santana e o macarrão com carne assada de Tia Edith (falecida em 2016). Tia Neide Santana é filha de Chico Santana, autor do hino da G.R.E.S3. Portela e de dona Ercília, famosa mãe de santo de Madureira. Tia Edith recriou o macarrão com carne assada, prato preferido de Paulo da Portela, muitas vezes preparado por ele durante as festas e almoços no Bar do Nozinho. Nascia, assim, a primeira edição da Feira, que reúne milhares de visitantes desde abril de 2008. Marquinhos se mostra preocupado em divulgar essa cultura do subúrbio porque acredita na força que a memória exerce no cotidiano da cidade, principalmente no que se refere às artes, à oralidade e a outros legados.

Quero poder cantar para os descendentes dos que construíram (e continuam a construir até hoje) a minha arte. Cantar para lembrar aos moradores dos morros e subúrbios do etnocídio a que somos submetidos diariamente pelos detentores e defensores do pensamento hegemônico. (CRUZ, 2015)

Na fase de planejamento do evento, convidou as yabás, uma a uma. A escolha dos pratos foi uma sugestão delas sobre o prato preferido ou o mais servido em suas casas (Quadro 1). Reunidas, as 16 matriarcas tradicionais da Grande Madureira, tornaram-se as yabás da Feira das Yabás. São elas: as pastoras (matriarcas das escolas de samba e grupos de jongo que conduzem as alas, "puxam" os sambas nos eventos e realizam shows) Tia Neném, Tia Surica, Tia Natércia e Tia Jussara. Descendentes de cantores e sambistas renomados: as tias Vera e Janaína de Jesus, Tia Selma Candeia, Tia Jane Pereira, Tia Rose, Tia Neide Santana, Tia Marlene, Tia Romana, Tia Nira, Tia Jane Carla, Tia Vera Caju e Tia Rosângela. A barraca de Tia Edith foi assumida por seus filhos e mantém o nome da matriarca, após sua morte. 


\begin{tabular}{|c|c|c|}
\hline $\begin{array}{l}\text { BARRACA } \\
\text { YABÁ }\end{array}$ & $\begin{array}{l}\text { CULINÁRIA } \\
\text { PRINCIPAL }\end{array}$ & $\begin{array}{l}\text { RELAÇÃO DE PARENTALIDADE E } \\
\text { ANTEPASSADOS }\end{array}$ \\
\hline TIA EDITH & $\begin{array}{l}\text { Macarrão com car- } \\
\text { ne assada }\end{array}$ & $\begin{array}{l}\text { Pioneira da FDY4; representava Paulo da } \\
\text { Portela (fundador da escola) }\end{array}$ \\
\hline TIA JANE CARLA & Cozido de peixe & Pastora da Ala das Baianas (Portela) \\
\hline TIA JANE PEREIRA & Jiló frito & $\begin{array}{l}\text { Viúva do compositor Luis Carlos da Vila } \\
\text { (Vila Isabel) }\end{array}$ \\
\hline TIA JUSSARA & Bobó de camarão & $\begin{array}{l}\text { Filha de Dona Balbina (pastora da Velha } \\
\text { Guarda Império Serrano) }\end{array}$ \\
\hline TIA MARLENE & $\begin{array}{l}\text { Feijoada; "Roupa } \\
\text { Velha" }\end{array}$ & $\begin{array}{l}\text { Sobrinha de Natal da Portela e Tia } \\
\text { Vicentina }\end{array}$ \\
\hline TIA NEIDE SANTANA & Angu à baiana & Filha de Chico Santana \\
\hline TIA NIRA & Peixe frito & Filha de Mestre Jaburu \\
\hline TIA ROMANA & Carré à mineira & $\begin{array}{l}\text { Imperiana, divorciada do sambista Ivan } \\
\text { Milanês }\end{array}$ \\
\hline TIA ROSANGELA & Tripa lombeira & Sobrinha de Tia Doca da Portela \\
\hline TIA ROSEMERI & Frango com quiabo & Esposa de Marquinhos de Oswaldo Cruz \\
\hline TIA SELMA CANDEIA & $\begin{array}{l}\text { Carne seca com } \\
\text { abóbora }\end{array}$ & Filha de Mestre Candeia Filho \\
\hline TIA SURICA & Mocotó & Cantora da Velha Guarda da Portela \\
\hline TIA VERA CAJU & Cozido & Pastora da Mangueira \\
\hline TIAS NATERCIA E SUELI & Vaca atolada & $\begin{array}{l}\text { Mãe e tia de Marquinhos de Oswaldo } \\
\text { Cruz }\end{array}$ \\
\hline TIAS NENÉM E AUREA & Rabada; & $\begin{array}{l}\text { Viúva e filha de Manaceia; cantora da } \\
\text { Velha Guarda da Portela }\end{array}$ \\
\hline TIAS VERA E JANAINA & Doces caseiros & Netas de Clementina de Jesus \\
\hline
\end{tabular}

Quadro 1: Relação das Yabás e o prato principal servido em suas barracas

Fonte: CHAO, 2019. A autora criou a tabela para esse artigo referente aos dados de campo entre março e abril de 2019.

A Feira das Yabás é um evento realizado em território público - o espaço da rua e da praça. Habermas (1984) classifica como "públicos" certos eventos quando eles, em contraposição às sociedades fechadas, são acessíveis a qualquer um. O curioso é que, apesar de ser um evento aberto, no qual os frequentadores não pagam para adentrar, a rua ganha um "status de privado", no sentido de pertencimento e de apropriação daquele espaço. É a sensação de "estar adentrando ao quintal de casa", o "lugar da festa", do "banquete à mesa" e do "chão para sambar". A produção do evento dispõe 16 barracas e 1 palco situados entre a Estrada do Portela (Madureira) e a Praça Paulo da Portela (Oswaldo Cruz) com mesas e cadeiras ao longo da via, banheiros químicos e camarim para as atrações musicais. Também há consumo e comércio de ambulantes, bares e residências que vendem alimentos e bebidas no entorno da Feira das Yabás.

$4 \quad$ FDY - Feira das Yabás 


\section{SOCIALIDADE E CONSUMO "NA RUA DE CASA"}

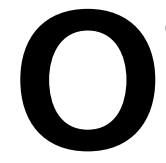

clima das edições da Feira recria a ambiência dos almoços em família, comemorações entre amigos, a "comida de vó" feita com qualidade e fartura. As pessoas demonstram sentir-se envolvidas, convidadas a "ir almoçar na casa" (rua) das yabás. Por isso, tomam o espaço como particular, como se tivessem sido formalmente convidadas para uma festa. Como justifica Habermas (1984), a representatividade dos eventos e festas na rua, desde o século $X V$, é dependente de uma circunvizinhança que se desenrole, se envolva.

A "comida de subúrbio" ressignificada na Feira das Yabás se identifica (ou combina) com o espaço da rua. Para Montanari (2008), o "gosto da geografia" não pertence ao passado, mas traz uma lembrança ou uma memória do não-vivido. $O$ território constitui um valor de referência absoluto nas escolhas alimentares. $\mathrm{O}$ autor enfatiza que a escolha do lugar é baseada em elementos da tradição. E ainda que seja inovadora, desenvolve-se em concomitância com vários fenômenos, tanto de caráter econômico quanto cultural (MONTANARI, 2008).

O "comer na rua" envolve a energia própria da socialidade que, para Maffesoli (2014, p. 5), "se investe nesses lugares, reais ou simbólicos, onde as tribos pós-modernas dividem os gostos (musicais, culturais, sexuais, esportivos, religiosos...) que servem de cimento (ethos) ao fato de estar-juntos". Para o autor, o lugar cria ligação; esta socialidade está relacionada às práticas de comensalidade, próprias da rua. $\mathrm{Na}$ Feira das Yabás, é possível observar as pessoas consumindo as refeições sentadas (ou não) em mesas dispostas no meio da rua, nas calçadas, nas varandas dos prédios. $\mathrm{E}$ se não há mesa, não tem problema. A bebida, geralmente cerveja e refrigerantes, ocupa baldes de gelo e as pessoas as colocam no chão. Em volta do balde, reúnem-se para conversar e, de pé, com os pratos às mãos, consomem petiscos. Também observamos os frequentadores que não necessariamente consomem os produtos das barracas da feira. Grupos levam seu próprio alimento em vasilhames, caixas térmicas e banquinhos. Em frente à calçada, organizam o espaço, onde a caixa térmica é transformada em mesa, os banquinhos ficam dispostos em volta da caixa. E todos se reúnem para o almoço de domingo, ligados ao que Maffesoli (2014) denomina de "um ideal comunitário", efeito de um elo estreito que une real/irreal, razão/ sensibilidade, visível/invisível, podendo evitar a estigmatização do "agir em comunidade" (MAFFESOLI, 2014). O autor defende que, no momento em que a comida se transformou em um bem difundido, esse código alimentar se embota, enquanto se afirma o valor do território como receptáculo de uma nova diferença: a comida geográfica (IDEM, 2014, p. 142). Por essa razão, o conceito de "cozinha de território" se mantém atual e a Feira das Yabás reproduz as diferentes relações de consumo (de bens e sensações) e sociabilidade (interações) no espaço "particular" da rua.

No início do século XX, essas caraterísticas de proximidade, a vontade de partiIhar emoções, experiências cotidianas e de estar juntos foram chamadas de sociabilidade, um conceito usado por Georg Simmel para evidenciar as interações dos indivíduos que caracterizam uma sociedade. Para Simmel, tudo que está no indivíduo é conteúdo; a sociação é a forma pela qual os indivíduos se agrupam em unidades que 
satisfazem seus interesses. Esses interesses (sensuais ou ideais, temporários ou duradouros, conscientes ou não) é que formam a base das sociedades humanas (SIMMEL, 1908, p.40-57, apud FILHO, E. 1983, p. 166).

Quando Maffesoli (2014) menciona que o mundo "é um conjunto de referências que eu partilho com outros", está enobrecendo a força da sociabilidade que costura firmemente as redes de solidariedade que solidificam as estruturas culturais. Estas estruturas de conjunto são compostas hoje pelo sensível, que por muito tempo foi negligenciado, reaparecendo de maneira intensa no cotidiano da vida social. Maia (2005) nos lembra que, na perspectiva maffesoliana, a "socialidade" pode ser caracterizada pelo relativismo do viver, pelo dado de grandeza e de trágico contidos no cotidiano. Hoje, porém, com o apoio de Michel Maffesoli podemos assumir a postura generosa de chegarmos perto de nosso objeto de pesquisa em constante movimento (MAIA, 2005a, p.77-79).

$\mathrm{Na}$ edição de março de 2019, foi realizada uma amostra para identificar e responder algumas curiosidades do campo quanto aos hábitos de consumo e outras percepções da Feira das Yabás ao seu público frequentador. A metodologia central da pesquisa é de ordem qualitativa. Foi utilizada a técnica a técnica de questionário on line para responder algumas curiosidades do campo, a exemplo dos pratos mais consumidos, as impressões dos frequentadores quanto à música, a gastronomia, os espaços da rua e o que define a Comida de Subúrbio representada na FDY. O questionário on-line utilizou perguntas abertas e de múltipla escolha, divulgado na página Suburbano da Depressão, do historiador Vitor G. Almeida no Facebook, entre 10 de março e 07 de abril de 2019. A amostra analisou dados de 160 respondentes que já haviam participado de alguma edição da Feira das Yabás. Sobre as idas e frequência ao evento, 33,8\% costumavam ir à FDY mais de 2 vezes ao ano; 31,3\% menos de 2 vezes ao ano; $17,5 \%$ tinham o costume de ir a quase todas as edições do ano e $17,5 \%$ visitavam a Feira pela primeira vez.

Sobre o consumo e preferência dos pratos servidos nas barracas das tias, selecionamos os cinco mais citados (Tabela 1):

\begin{tabular}{|l|l|l|}
\hline Peixe frito & barraca de tia Nira & $30,6 \%$ \\
\hline Jiló frito & barraca de tia Jane Pereira & $29,3 \%$ \\
\hline Doces caseiros & barraca das tias Vera e Janaina de Jesus & $27,4 \%$ \\
\hline Vaca atolada & barraca das tias Natércia e Sueli & $24,80 \%$ \\
\hline Angu à baiana & barraca de tia Neide Santana & $22,3 \%$ \\
\hline
\end{tabular}

Tabela 1: Pratos servidos nas Barracas da Feira das Yabás.

Fonte: Tabela criada pela autora. 


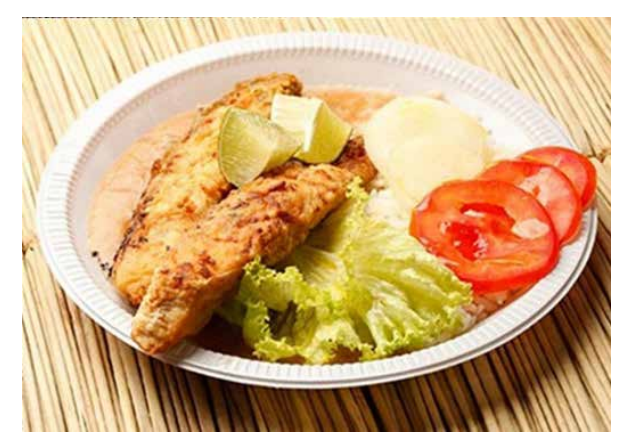

Figura 2 - Prato de Peixe Frito - barraca de Tia Nira - FDY.

Fonte: <http://www.fdy.com.br>, acesso em abril/2014.

O consumo está para além de técnicas e métodos comerciais. É uma maneira inventiva e diferenciada de fazer e usar. Existe uma arte de refazer as práticas do espaço, maneiras de frequentar um lugar, processos complexos da arte culinária e modos de dar confiabilidade a ritos (CERTEAU, 1998). A estes "reempregos", Certeau (1998) chama de "bricolagem". Trata-se de novas maneiras de fazer e consumir a partir da possibilidade de uso dos espaços em branco.

A comida oferecida na rua representa uma reconquista criativa de espaços públicos, do interesse dos atores sociais, nas diversas formar de compartilhar símbolos, de comungar. $\mathrm{O}$ ato de vincular o consumo com a cidadania em um lugar de valor cognitivo é "útil para pensar e agir, significativa e renovadoramente na vida social" (CANCLínI, 2008, p.72).

A representação das yabás personifica a cultural local, a tradição da culinária brasileira influenciada principalmente pelas culturas africana e europeia. O próprio significado do termo yabá como "rainha", "maternal", concede a essas matriarcas, uma "autoridade" que Certeau confere ao novo uso desses espaços nas práticas cotidianas: "[...] práticas de espaços urbanos, utilização de ritualizações cotidianas, reempregos e funcionamentos da memória através das 'autoridades' que possibilitam (ou permitem) as práticas cotidianas" (CERTEAU,1998, p. 42). São tais "maneiras de fazer cotidianas" do homem comum que fazem com que ele não "consuma" ideias, valores e produtos de forma passiva, mas com uma "resistência" às imposições do mercado e dos poderes sociais.

\section{CONSIDERAÇÕES FINAIS}

- sse artigo surgiu a partir do convite em participar da /l Jornada Consumo e Sociabilidades da ESPM Rio, realizada em maio de 2019. Na época, ainda sob a emoção e saudade do Professor João Maia, sempre tão presente no campo de pesquisa, pude apresentar a Feira das Yabás e suas matriarcas como elementos científicos da minha tese de doutoramento junto ao Programa de Pós Graduação em Comunicação da UERJ.

Investigar as práticas culturais do cotidiano simples da cidade, atreladas à história cultural, à memória e às tradições me instiga o desejo de manter costumes e propor a divulgação da importância deste patrimônio da cultura brasileira como formadora de identidade e resistência da cidade. No artigo pude particularizar a 
importância das observações, da escuta às "histórias miúdas", do retorno às memórias coletivas e da vivência ativa no campo científico como uma metodologia de pesquisa em comunicação, valorizando tais movimentos de sociabilidade e consumo como formas de vinculação social.

É importante evidenciar as yabás como agentes culturais e comunicacionais projetando ações, a identidade da comida, os modos de fazer, bem como as práticas de comensalidade e de "estar junto" na rua, lugar da festa. As yabás reproduzem, a seu modo, a culinária tradicional carioca, recriando inclusive, novas formas de comensalidade nos almoços de domingo, além de favorecer o estar-junto na rua, referências dos almoços de quintal dos antepassados culturais do bairro.

Os espaços de lazer apresentados, onde as representações sociais se manifestam, em especial em Oswaldo Cruz e Madureira representam também um território de comunicação e culturas, sobretudo de produção de sentidos onde podem ser compreendidos valores, memórias e símbolos de pertencimento, marcados também pela afeição. Pensando cultura, não somente como uma manifestação popular, mas sim como um conceito formador da identidade de uma comunidade, de criação, de trocas entre demais culturas, que sofrem alterações com o passar dos anos, ressaltamos tais espaços característicos do subúrbio carioca para compreender as relações de sociabilidade e comensalidade em torno de bens culturais como a culinária e a música do lugar.

A Feira das Yabás, enquanto momento e lugar de festa, constitui uma outra forma de experimentar a vida social, marcada pelo lúdico, pela exaltação dos sentidos e das emoções coletivas.

\section{REFERÊNCIAS}

BERNARDES, Lysia M. C.; SOARES, Maria Theresinha de Segadas. Rio de Janeiro, cidade e região. Rio de Janeiro: Departamento Geral de Documentação e Informação Cultural da Secretaria Municipal de Cultura da Prefeitura da Cidade do Rio de Janeiro, 1987.

CANCLÍNI, Nestor G. Consumidores e Cidadãos. Rio de Janeiro: UFRJ, 2008.

CERTEAU, Michel De. A. Invenção do Cotidiano: Artes de Fazer. 3. ed. Petrópolis: Vozes, 1998.

CHAO, Adelaide. Comunicação e Cultura: a Feira das Yabás / 2015. 104 f. Trabalho de conclusão de curso (dissertação) de mestrado em Comunicação. Universidade do Estado do Rio de Janeiro. Rio de Janeiro, 2015.

CHAO, Adelaide. Tem caroço nesse angu: a ressignificação do subúrbio carioca a partir da culinária das Yabás da Grande Madureira /2018. 68f. Trabalho de Qualificação de Doutorado em Comunicação. Universidade do Estado do Rio de Janeiro. Rio de Janeiro, 2018

CRUZ. Marquinhos de O. Depoimento extraído site <http://www.marquinhosdeoswaldocruz.com/ historia/>, acesso em 14 fev.2015.

CUNHA, Washington D dos S. Samba, história e territorialidade: uma história da Grande Madureira. In: RIBEIRO, Ana et al. (orgs.) Memórias, territórios e identidades: diálogos entre gerações na região da Grande Madureira. Rio de Janeiro: Mórula Editorial, 2019.

FERNANDES, Nelson da Nóbrega. Escolas de samba: sujeitos celebrantes e objetos celebrados. Rio de Janeiro 1928|1949. Rio de Janeiro: Secretaria de Culturas, Departamento Geral de Documentação e Informação Cultural, Arquivo Geral da Cidade do Rio de Janeiro, 2001. 

uma observação entre práticas culturais, memória e tradição

FILHO, Evaristo de M. Georg Simmel: sociologia. Trad. Carlos Alberto Pavanelli et al. São Paulo: Ática, 1983.

GEERTZ, Clifford. A interpretação das culturas. Rio de Janeiro: LTC, 2008.

GEERTZ, Clifford. O saber local: novos ensaios em antropologia interpretativa. Trad. Vera M. Joscelyne. Petrópolis: Vozes, 1997.

HABERMAS, J. Mudança estrutural da esfera pública: investigações quanto a uma categoria da sociedade burguesa. Tradução Flávio R. Kothe. Rio de Janeiro: Tempo Brasileiro, 1984.

MAFFESOLI, M. Homo eroticus: comunhões emocionais. Tradução Abner Chiquieri. Rio de Janeiro: Forense, 2014.

MAFFESOLI, Michel. O tempo das tribos: o declínio do individualismo nas sociedades de massa. Rio de Janeiro: Forense Universitária, 1998.

MAIA, João. As novas formas de sociabilidade dos espaços urbanos contemporâneos. Revista Contemporânea, v. 1, n.1, p.47-55, $1^{\circ}$.sem/2003.

MAIA, João. Cidade, cidadania e cultura comunitária. Revista Comunicação e Informação, v.8, n.2: p. 118-128, jul./dez. 2005b.

MAIA, João. Michel Maffesoli e a cidade partilhada. FAMECOS, n. 26. Porto Alegre, abril, $2005 a$.

MONTANARI, Massimo. Comida como cultura. Tradução Letícia M. de Andrade. São Paulo: Senac, 2008.

OLIVEIRA, Marcos Piñon de. Soluções e esperança nas fronteiras da cidade. Caderno Globo Universidade, Globo, Rio de Janeiro, v.1, n.2, mar. 2013.

RIBEIRO, Ana Paula. CID, Gabriel. VARGUES, Guilherme. Samba, história e territorialidade: uma história da Grande Madureira. In: RIBEIRO, Ana et al. (orgs.). Memórias, territórios e identidades: diálogos entre gerações na região da Grande Madureira. Rio de Janeiro: Mórula Editorial, 2019.

SILVA, Marília T. Barboza; SANTOS, Lygia Lopes dos. Paulo da Portela: traço de união entre duas culturas. Rio de Janeiro: Edição Funarte (Coleção MPB; v. 3), 1980 .

SOARES, M. T. S. Divisões principais e limites externos do Grande Rio de Janeiro. In: Anais da Associação dos Geógrafos Brasileiros, São Paulo: A.G.B., v. XII,1960

SOARES, M.T.S. Bairros, bairros suburbanos e subcentros. Espaço Aberto, PPGG UFRJ, v.1, n.1, p.143154, 2011.

YUDICE, George. A conveniência da cultura: usos da cultura na era global. 2.ed. Trad. Marie-Anne Kremer Belo Horizonte: Editora UFMG, 2013. 